\title{
An Efficient Method to Improve Practical Knowledge - Technical Lab Report Writing
}

\author{
M.Sirisha ${ }^{1}$, Mohebbanaaz $^{2}$, Joseph rajiv ${ }^{3}$, Dr. Divya Nalla ${ }^{4}$. \\ ${ }^{2}$ Ph.D scholar, Dept. of ECE, VNR Vignana Jyothi Institute of Engineering and Technology, Hyderabad \\ ${ }^{1,3}$ Assistant Professor, ${ }^{4}$ Principal, Nalla Malla Reddy Engineering College, Hyderabad \\ 1madiraju.sirisha@gmail.com, ${ }^{2}$ mohebbanaaz@gmail.com, ${ }^{3}$ joshephrajivk@ gmail.com, ${ }^{4}$ divyanalla@nmrec.edu.in
}

\begin{abstract}
The present curriculum in the engineering education is lacking the practical knowledge development in the students. Practical knowledge plays an important role, and this is the major point of view for students to get into the industrial roles. Conducting an experiment in the curriculum labs and publishing the results in general way doesn't improve the practical knowledge. Always there will be a difference in the theoretical and practical values of an experiment due to different types of unavoidable errors. Students should be able to know the reason behind that difference which improves their practical knowledge and troubleshooting of any problem.

This paper gives an efficient method called as Technical lab report writing to improve practical knowledge of a student. We, being post graduates in ECE, the technical lab report writing discussed here is all about electronics. This has been implemented in the II/II semester of B.Tech ECE (December 2018 to March 2019) and found improvement in the four qualities Q1, Q2, Q3, Q4 (Critical thinking, New ideas, Confidence levels, Communication skills) when they come to III/I semester of B.Tech ECE.
\end{abstract}

Key words: Technical lab report writing, practical knowledge, curriculum improvement.

\section{Introduction}

In present academic curriculum, lab experiments are performed in a traditional way. Just conducting the lab experiments does not fulfil the aspect of acquiring the practical knowledge [1], [3], [4]. Always theoretical values differ from practical values. It is found that the lab experiment only doesn't make the students to think and analyse the technical reasons behind the difference between theoretical and practical values.

No physical quantity can be measured perfectly without any errors. This means that the value of a quantity measured at one point of time will change when second time measured. This says that never a quantity measured with certainty. Still there are so many ways that can be taken to reduce the errors in the experiment. Experimental errors are not that are frequently referred mistakes, miscalculations or any blunder. These types of errors occur from wrong measurement of width or length, measuring voltage at wrong portion of an electronic circuit.

Experimental errors are those that occur in the procedure of measurement and these errors cannot be eliminated even by repeating the experiment again and again [2]. The experimental errors are classified as

\section{A. Systematic Errors \\ B. Random Errors.}

\section{A.SYSTEMATIC ERRORS}

Systematic errors are the errors which affect the accuracy of an experiment (Or) it is said that Accuracy is mostly affected by systematic errors [5]. Analysis of such type of errors becomes difficult. By doing statistical analysis normal errors can be reduced but this does not work for systematic errors. These errors are difficult to detect, if found they can only be eliminated by changing the total methodology.

The sources or origin of systematic errors is due to faulty calibration of an instrument or poor maintenance of equipment or parallax error.

\section{B.RANDOM ERRORS}

Random errors are the errors which affect the precision of a measurement or precision is mostly affected by random errors. Random errors can be considered as two-sided errors. In the absence of other types of errors, frequent measurements of values can give results that swing between the true or accepted value. In measuring process, measurements bounded to random errors differ from each other. This is due to variations that are random or unpredictable. We can improve the precision of measurements by repeating the measurements continuously. Random errors are easy to detect and can be reduced by using statistical analysis or by repeating the measurement or by correcting/changing the measurement methodology or technique.

Random errors mainly occur due to problems in estimating value or a number that lies between the lines (graduations) on an instrument or due to inability to note 

readings as the readings always fluctuate during the measurement.

In the normal experiment records all these are not discussed. In the proposed technical report writing all these errors and their origins are discussed. An error percentage is also calculated to know the acceptable deviation of the error in that experiment. This makes the students to find out the reason behind the deviation in values of experiment and helps the student to get accurate results.

\section{Proposed Methodology}

With this proposed methodology the student will have knowledge of the background due to which the error occurred. By writing this type of technical lab report and calculating the error in the experiment, student will be able to analyse the reason behind it. This improves his knowledge in the materials, specifications, types of equipment to be used in an experiment.

Experimental errors in the report should describe the precision and accuracy of the measurements in the experiment. Regular or common methods for finding accuracy and precision of an experiment are:
A. Percent Error
B. Percent Difference.

\section{A.PERCENT ERROR}

This refers the accuracy of the measurement. This is measured by the difference between the measured value (practical value) and the actual value (theoretical value) to be obtained.

It is defined as the ratio of the difference between the measured value $(\mathrm{M})$ and the theoretical value or actual value $(\mathrm{T})$ to theoretical or actual value $(\mathrm{T})$. It is given by

$$
\% E r=\left(\frac{|M-T|}{T}\right)
$$

\section{B.PERCENT DIFFERENCE}

This refers the precision of the measurement in an experiment. It is the measure of precision and defined by taking the ratio of difference between two measured values or practical values or experimental values M1 and M2 to that of average of the two values. Percent difference is calculated as:

$$
\% D f=\left(|M 1-M 2| /\left(\frac{M 1+M 2}{2}\right)\right)
$$

After calculation of accuracy and precision the reasons for that must be tabulated. A sample technical lab report is discussed on an Electronic Devices and Circuits (EDC) experiment, Full Wave Rectifier.

\section{Results and Discussions}

\section{SAMPLE TECHNICAL REPORT WRITING}

Sample of a technical report explains how efficiently this method works. A Full Wave Rectifier has a centre tapped transformer and diodes. It converts Alternating Current to pulsating Direct Current and the theoretical efficiency $(\eta)$ and ripple factor(r) for the full wave rectifier is 81.2 and $0.48(\mathrm{r})$.

$$
\text { Efficiency } \eta=P_{d c} / P_{a c}
$$

Where $P_{a c}=$ AC Power at the input and

$$
P_{d c}=\text { DC power at the output }
$$

$$
\text { Ripple factor } r=\sqrt{\left(\frac{V_{r m s}}{V_{d c}}\right)^{2}-1}
$$

Where $V_{r m s}=$ RMS voltage and $V_{d c}=\mathrm{DC}$ voltage

Calculate errors using above formulae. If theoretical value and practical values are same then percent error and percent difference will be zero which is not possible. In General we get $\% \mathrm{Er}$ and $\% \mathrm{Df}$ values close to zero. If values deviation is less than $10 \%$ then they are acceptable. If we get values greater than $10 \%$ then the student needs to find the causes for value deviation.

In the laboratory the efficiency got is 76.8 and 0.42.Calculating errors using above formulae we get

Percent Error of efficiency $(\eta)$

$$
\begin{aligned}
\% E r & =\left(\frac{|76.8-81.2|}{81.2}\right) \\
& =0.054
\end{aligned}
$$

Percent Error of ripple factor $(r)$

$$
\begin{aligned}
\% E r & =\left(\frac{|0.42-0.48|}{0.48}\right) \\
& =0.0125
\end{aligned}
$$

Percent difference of efficiency $(\eta)$

$$
\begin{aligned}
& \% D f=\left(|76.7-81.2| /\left(\frac{76.8+81.2}{2}\right)\right) \\
& =0.055
\end{aligned}
$$

Percent Error of ripple factor $(r)$ 


$$
\% D f=\left(\begin{array}{c}
\text { Journal of Engineering E } \\
|0.42-0.48| /\left(\frac{0.42+0.48}{2}\right)
\end{array}\right)
$$

As the deviation in ripple factor is greater than $10 \%$ student needs to analyze and find the cause of deviation. Through the following possible reasons, students are asked to troubleshoot the circuit and list out the problem for more deviation.

The possible reasons for deviation of practical values from theoretical are:

1. The transformer centre tapping may not be accurate which leads to the difference in the voltage in turn the current value deviates

2. Diodes used in the experiment may of same type, but the specification may vary minutely.

3. The source used for generating AC may have Electro Magnetic Compatibility/ Electro Magnetic Interference (EMC/EMI) effect.

4. The power supply used may not be grounded exactly.

5. The connecting wires used also afford some resistance.

Then the student finds out the reason and makes the necessary adjustments. Thereafter both errors are calculated once again. It was found that the circuit was not grounded properly. After connecting to the ground properly student got value of efficiency as 79.8 and ripple factor as 0.46 .

Percent Error of efficiency $(\eta)$

$$
\begin{aligned}
\% E r= & \left(\frac{|79.8-81.2|}{81.2}\right) \\
& =0.017
\end{aligned}
$$

Percent Error of ripple factor $(r)$

$$
\begin{aligned}
\% E r & =\left(\frac{|0.46-0.48|}{0.48}\right) \\
& =0.041
\end{aligned}
$$

Percent difference of efficiency ( $\eta$ )

$$
\begin{aligned}
& \% D f=\left(|79.8-81.2| /\left(\frac{79.8+81.2}{2}\right)\right) \\
& =0.0175
\end{aligned}
$$

Percent Error of ripple factor $(r)$

$$
\begin{aligned}
& \% D f=\left(|0.46-0.48| /\left(\frac{0.46+0.48}{2}\right)\right) \\
& =0.043
\end{aligned}
$$

Table 1 gives the comparison of errors in percentages while calculating Efficiency ( $\eta$ ) and Ripple nations, Volume 33, January 2020, Special issue, eISSN 2394-1707 Factor(r) before and after identifying problem. Figure 1 shows the comparison of errors for efficiency $(\eta)$. Figure 2 shows the comparison of errors for ripple factor(r). It is said from figure 1; figure 2 that after analysis percentage errors have been reduced.

Table 1: Comparison of errors before and after analysis

\begin{tabular}{|c|c|c|c|c|}
\hline \multirow{2}{*}{} & \multicolumn{2}{|c|}{ Before Analysis } & \multicolumn{2}{c|}{ After analysis } \\
\cline { 2 - 5 } & $\begin{array}{c}\text { Efficiency } \\
(\mathrm{\eta})\end{array}$ & $\begin{array}{c}\text { Ripple } \\
\text { Factor } \\
(\mathrm{r})\end{array}$ & $\begin{array}{c}\text { Efficienc } \\
\mathrm{y}(\mathrm{\eta})\end{array}$ & $\begin{array}{c}\text { Ripple } \\
\text { Factor } \\
(\mathrm{r})\end{array}$ \\
\hline $\begin{array}{c}\text { Percent } \\
\text { error(Er) }\end{array}$ & $5.4 \%$ & $12.5 \%$ & $1.7 \%$ & $4.1 \%$ \\
\hline $\begin{array}{c}\text { Percent } \\
\text { difference } \\
\text { (Df) }\end{array}$ & $5.5 \%$ & $13.3 \%$ & $1.75 \%$ & $4.3 \%$ \\
\hline
\end{tabular}

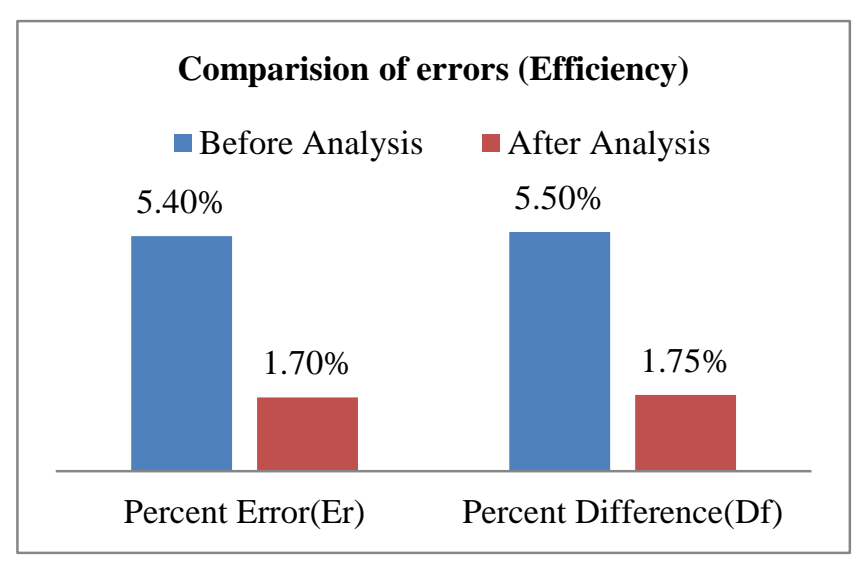

Figure 1: Comparison of errors for efficiency

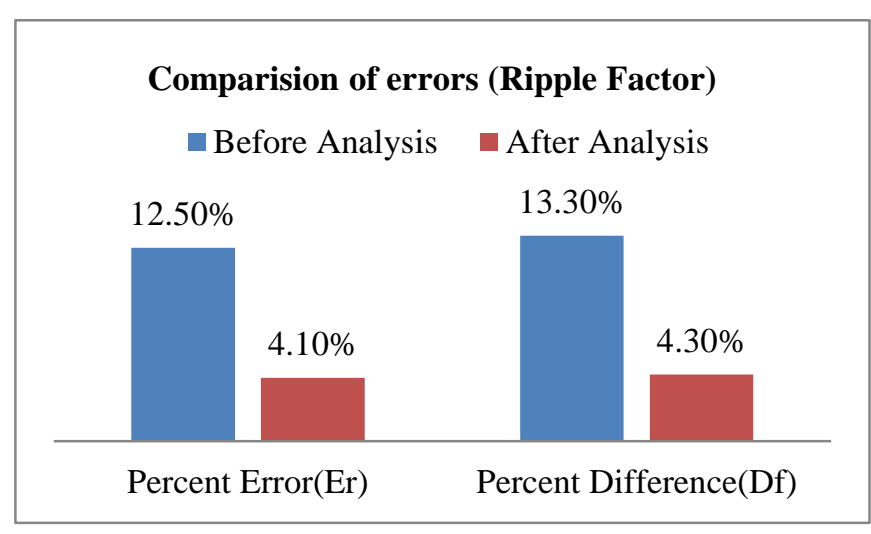

Figure 2: Comparison of errors for ripple factor(r)

Figure 3 shows that after finding the reasons for deviation in efficiency and ripple factor, Percent error and Percent difference have been reduced This technical report 

writing gives a clear idea for a student about the components, their working and their specifications which helps them to work on a project by themselves.

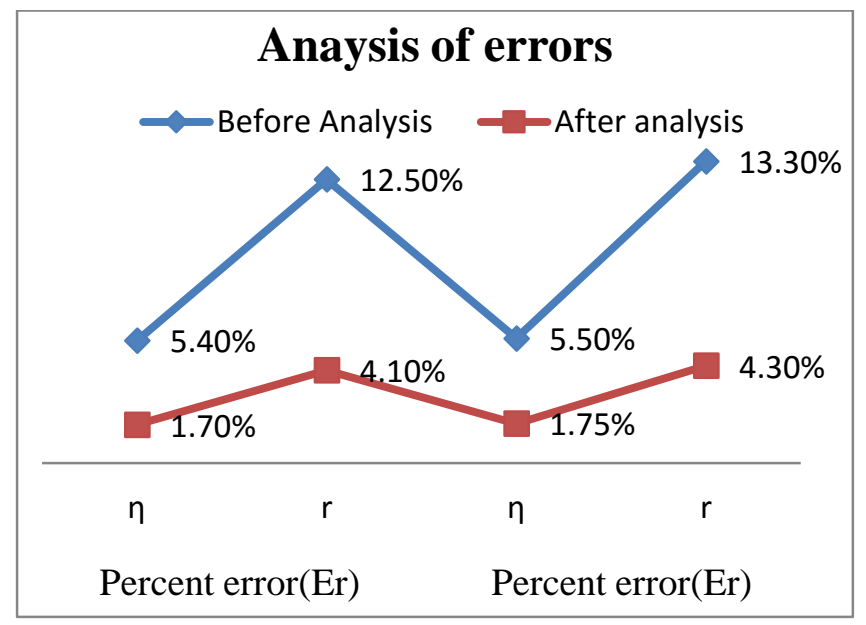

Figure 3: Analysis of errors

It is observed that, with the implementation of this report writing students have been improved in the following ways:

1. Critical thinking (Q1): They started troubleshooting any type of network on their own. As they gain the knowledge of working of the components, troubleshooting has become easy to them.

2. New Ideas (Q2): As the practical knowledge improves, they started implementing new ideas and so many got even succeeded in their ideas.

3. Confidence levels (Q3): Fear is just lack of knowledge. Once they gain knowledge of the practical problems and solution to them, their confidence levels got boosted up and made them bold enough to face any situation.

4. Communication Skills (Q4) : When they started this report writing, their thought process got changed and they started participating in the competitions like project ideas, poster presentation, paper presentation etc. This increased their communication skills.

Before this idea got implemented the percentage of students having above qualities was very few. After implementing this idea, the percentage of students having above qualities got increased and also the level of these qualities got increased in the students who already possess them.

This technical report writing has been implemented in the labs of II/II of B.Tech ECE in the period from December 2018 to March 2019. By the time they reached III/I, all the above mentioned qualities got improved in them. They started implementing new project and attended so many hackathons and stood in the top three.
The following Table 2 shows the analysis of some students when they are in II/II and III/I, represented qualities in percentages:

Table 2. Comparisons of four qualities (Q1, Q2, Q3, Q4) in the students of II/II and III/I semesters

\begin{tabular}{|c|c|c|c|c|c|c|c|c|}
\hline \multirow{2}{*}{ R.No. } & \multicolumn{2}{|c|}{ Q1 } & \multicolumn{2}{c|}{ Q2 } & \multicolumn{2}{c|}{ Q3 } & \multicolumn{2}{c|}{ Q4 } \\
\cline { 2 - 9 } & II/II & III/I & II/II & III/I & II/II & III/I & II/II & III/I \\
\hline $17-410$ & 20 & 75 & 15 & 70 & 25 & 80 & 10 & 80 \\
\hline $17-450$ & 15 & 70 & 10 & 65 & 20 & 75 & 20 & 90 \\
\hline $17-483$ & 25 & 80 & 20 & 75 & 30 & 85 & 30 & 85 \\
\hline $17-4 A 1$ & 30 & 90 & 25 & 85 & 35 & 95 & 35 & 90 \\
\hline $17-4 C 9$ & 20 & 85 & 15 & 80 & 25 & 90 & 40 & 95 \\
\hline $17-4 D 6$ & 40 & 90 & 35 & 90 & 45 & 95 & 30 & 85 \\
\hline
\end{tabular}

The Figure 4 shows the comparison of four qualities of the students in II/II and III/I semesters of ECE B.Tech. This is a normal bar graph representation of all the values in percentages.

Comparision of four qualities

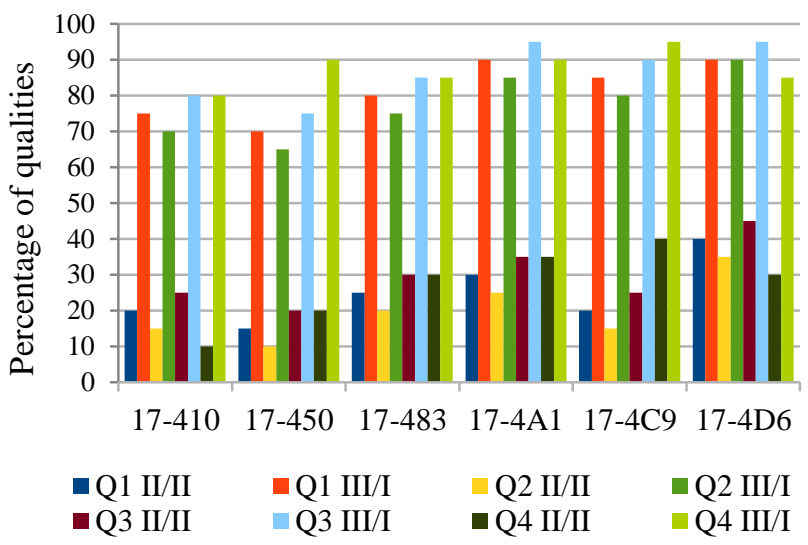

Figure 4: Comparisons of four qualities of students in II/II and III/I semesters

It is clear from the Figure 4 that the qualities are improved a lot after implementing this technical report writing in the lab.

\section{Conclusion}

This technical lab report writing is very much efficient from the traditional way of tabulating the measured values and writing the results. This way of investigating the results, finding the errors and reasons behind those errors leads a student to acquire more practical knowledge. This will also improve the students thought process and also improves the four qualities Q1, Q2, Q3, Q4 (Critical thinking, New ideas, Confidence levels, Communication skills) and changes their approach towards troubleshooting a problem. 


\section{References}

[1]Farrokh Attarzadeh, Deniz Gurkan and Driss Benhaddou, "Innovative Improvements to Engineering Technology Laboratory Education to Engage, Retain and Challenge Students of the 21st Century", Proceedings of ASEE Gulf-Southwest Annual Conference, Southern University and A \& M College American Society for Engineering Education, 2006.

[2] Jean-Claude Thom, AnoopAnoop Desai," Interactive Learning Modules for Innovative Pedagogy in Circuits and Electronics", 38th ASEE/IEEE Frontiers in Education Conference, F2A-7, Saratoga Springs, N, October $22-25,2008$

[3] Matthew F. Kazmierczak, Josh James, "Losing the Competitive Advantage? The Challenge for Science and Technology in the United States", aea, pp. 4, February 05. http://www. Aeanet .org/publications /IDJJ _AeA_ Competitiveness .asp

[4] Report of National Mission on Education Through information \& Communication Technology [ICT], Government of India, page $15,2008$.

[5] RobinBradbeer, "The Effectiveness of Teaching Introductory Electronics in an Integrated Teaching Studio Environment", International Journal of Engg. Education, Vol. 15, No. 5, pp. 344352, 1999. 